\title{
Evaluation of Gentamicin-Entrapped Solid Lipid Microparticles Formulated with a Biodegradable Homolipid from Capra hircus
}

\author{
FC Kenechukwu ${ }^{1 *}$, CE Umeyor ${ }^{2}$, MA Momoh ${ }^{1}$, JDN Ogbonna ${ }^{1}$, SA Chime ${ }^{3}$, PO \\ Nnamani ${ }^{1}$ and AA Attama ${ }^{1}$ \\ ${ }^{1}$ Department of Pharmaceutics, University of Nigeria, Nsukka 410001, ${ }^{2}$ Department of Pharmaceutics and Pharmaceutical \\ Technology, Nnamdi Azikiwe University, Awka, ${ }^{3}$ Department of Pharmaceutical Technology and Industrial Pharmacy, University \\ of Nigeria, Nsukka 410001, Nigeria
}

*For correspondence: Email: chimafrankduff@yahoo.com; frankline.kenechukwu@unn.edu.ng; Tel: +234 8038362638; Fax: $+234-42-771709$

Received: 5 October 2013

Revised accepted: 15 June 2014

\begin{abstract}
Purpose: To formulate solidified reverse micellar solutions (SRMS)-based solid lipid microparticles (SLMs) using homolipid from Capra hircus, and evaluate its suitability for the delivery of gentamicin. Methods: SLMs were formulated by melt-emulsification using SRMS $115 \%$ w/w Phospholipon® $90 G$ in $35 \%$ w/w Capra hircus), PEG 4000 and gentamicin (1.0, 2.0 and $3.0 \%$ w/w), and characterized with respect to size, morphology, encapsulation efficiency (EE) and $\mathrm{pH}$-dependent stability. In vitro release of gentamicin from the SLMs was performed in phosphate buffer (pH 7.4) while bioevaluation was carried out using clinical isolates of Pseudomonas aeruginosa and Staphylococcus aureus.

Results: Stable and discrete SLMs of size range $1.47 \pm 0.02$ to $3.55 \pm 0.09 \mu \mathrm{m}$ were obtained. The SLMs showed a biphasic pattern of drug release and exhibited time-dependent and capacity-limited bioactivity. Overall, SLMs containing $2 \%$ w/w SRMS, $3 \% \mathrm{w} / \mathrm{w}$ gentamicin and PEG 4000 entrapped the highest amount of drug, released $99 \%$ of drug and gave the highest inhibitory zone diameter (IZD) against the organisms within $420 \mathrm{~min}$, while plain gentamicin gave the least.

Conclusion: SRMS-based SLMs prepared with homolipid from Capra hircus offers a suitable delivery system for gentamicin.
\end{abstract}

Keywords: Solid lipid microparticles, Gentamicin, Capra hircus, Phospholipon® 90 G, Solidified reverse micellar solution

Tropical Journal of Pharmaceutical Research is indexed by Science Citation Index (SciSearch), Scopus, International Pharmaceutical Abstract, Chemical Abstracts, Embase, Index Copernicus, EBSCO, African Index Medicus, JournalSeek, Journal Citation Reports/Science Edition, Directory of Open Access Journals (DOAJ), African Journal Online, Bioline International, Open-J-Gate and Pharmacy Abstracts

\section{INTRODUCTION}

Sustained-release formulations offer numerous advantages compared to conventional dosage forms $[1,2]$. The proven safety and efficacy of lipid-based carriers make them potential alternative drug carrier materials to polymers as well as attractive candidates for preparing lipidbased formulations. These formulations allow for controlled/sustained drug delivery, among other benefits [3-5]. Solidified reverse micellar delivery systems (SRMDS) are lipid-based biodegradable matrix drug delivery systems [6], and have been widely investigated as potential drug delivery systems for drugs which encounter penetration and absorption problems [7,8]. Gentamicin, an aminoglycoside antibiotic used in the control of severe Gram-positive and Gram-negative microbial infections, is limited by poor absorption, low bioavailability and toxicity [9-11]. By tactical 
engineering of lipid drug delivery systems (LBDDS) such as solidified reverse micellar solution-based solid lipid microparticles (SRMSbased SLMs), these problems could be surmounted. Researchers have used this novel technology to increase the overall efficacy while minimizing toxicity of gentamicin [4,5,12-17]. Homolipids and heterolipids have gained renewed interests as excipients for LBDDS [15]. Homolipids are esters of fatty acids with various alcohols. Previous studies on LBDDS using a homolipid from goat fat (Capra hircus) and containing either hydrophilic or lipophilic drugs demonstrated positive results $[16,17]$. Similarly, Phospholipon® 90 G (P90G) has been shown to be a good excipient in the formulation of SRMSbased SLMs [18].

Consequently, the objectives of this study were to formulate SRMS (lipid matrix) consisting of P90G and Capra hircus, and SRMS-based SLMs containing gentamicin using melt-emulsification technique and evaluate the in vitro dissolution and bioactivity of gentamicin from such a delivery system.

\section{EXPERIMENTAL}

\section{Materials}

Gentamicin pure sample (JUHEL Pharmaceutical Limited, Awka, Nigeria), goat fat (a biodegradable homolipid was obtained from Capra hircus and purified in our laboratory), Phospholipon® 90G (Phospholipid GmbH, Köln, Nattermann, Germany), poloxamer 188 (Sigma Aldrich, Spain), polyethylene glycol 4000 (Acros Organics, USA), monobasic potassium phosphate, sodium hydroxide and concentrated Table 1: Composition of the SLMs formulation hydrochloric acid (BDH, England) and distilled water (Lion water, UNN, Nigeria).

\section{Extraction and purification of homolipid from Capra hircus}

The homolipid was extracted from the adipose tissue of Capra hircus by wet rendering following standard procedures $[16,17]$.

\section{Preparation of lipid matrix (SRMS) and solid lipid microparticles (SLMs)}

Lipid matrix consisting of mixture of $35 \% \mathrm{w} / \mathrm{w}$ goat fat (homolipid) and $15 \%$ w/w Phospholipon ${ }^{\circledR}$ 90G (P90G) was prepared by fusion method [13]. Briefly, the goat fat and P90G were weighed using electronic balance (Mettler H8, Switzerland), placed into a crucible, melted together at $75{ }^{\circ} \mathrm{C}$ on a thermo-regulated water bath shaker (Heto, Denmark) and stirred thoroughly. Thereafter, the mixture was allowed to cool and solidify at room temperature to obtain the lipid matrix (SRMS).

For the preparation of the SLMs, the meltemulsification technique [19] was adopted. In each case, the SRMS was melted at $75^{\circ} \mathrm{C}$, and the aqueous phase containing PEG-4000 and poloxamer 188 at the same temperature was added to the SRMS with gentle stirring with a magnetic stirrer (SR 1 UM 52188, Remi Equip., India), and the mixture was further dispersed with

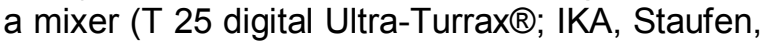
Germany) at $8000 \mathrm{rpm}$ for $5 \mathrm{~min}$. The SLMs suspension obtained after cooling at room temperature was then lyophilized using a freezedryer (Amsco GT3, Germany).

\begin{tabular}{lcccc}
\hline Batch & $\begin{array}{c}\text { PEG 4000 } \\
(\mathbf{g})\end{array}$ & $\begin{array}{c}\text { Poloxamer 188 } \\
(\mathbf{g})\end{array}$ & $\begin{array}{c}\text { Gentamicin } \\
(\mathbf{\%} \mathbf{w} / \mathbf{w})\end{array}$ & $\begin{array}{c}\text { Lipid base } \\
(\mathbf{1 5 \% w / w ~ P 9 0 G ~ i n ~ 3 5 \% w / w ~} \\
\text { GF) } \mathbf{( g )}\end{array}$ \\
\hline $\mathrm{A}_{1}$ & & & & 4.0 \\
$\mathrm{~A}_{2}$ & 1.0 & 2.0 & 1.00 & 3.0 \\
$\mathrm{~A}_{3}$ & 2.0 & 2.0 & 1.00 & 2.0 \\
$\mathrm{~B}_{1}$ & 3.0 & 2.0 & 1.00 & 4.0 \\
$\mathrm{~B}_{2}$ & 1.0 & 2.0 & 2.00 & 3.0 \\
$\mathrm{~B}_{3}$ & 2.0 & 2.0 & 2.00 & 2.0 \\
$\mathrm{C}_{1}$ & 3.0 & 2.0 & 2.00 & 4.0 \\
$\mathrm{C}_{2}$ & 1.0 & 2.0 & 3.00 & 3.0 \\
$\mathrm{C}_{3}$ & 2.0 & 2.0 & 3.00 & 2.0 \\
$\mathrm{D}_{1}$ & 3.0 & 2.0 & 3.00 & 4.0 \\
$\mathrm{D}_{2}$ & 1.0 & 2.0 & - & 3.0 \\
$\mathrm{D}_{3}$ & 2.0 & 2.0 & - & 2.0 \\
\hline
\end{tabular}

Note: Batches $A_{1}-A_{3}, B_{1}-B_{3}$ and $C_{1}-C_{3}$ are gentamicin-loaded SLMs while batches $D_{1}-D_{3}$ are unloaded (zerodrug) SLMs; P90G = Phospholipon ${ }^{\circledR}$ 90G, GF = goat fat; each formulation was made up to $100 \% \mathrm{w} / \mathrm{W}$ with distilled water 
Particle size analysis and morphological characterization of SLMs

The above procedure was repeated using PEG and gentamicin (1.0, 2.0 and $3.0 \% \mathrm{w} / \mathrm{w})$ and lipid matrix $(4.0,3.0$ and $2.0 \% \mathrm{w} / \mathrm{w})$, to obtained gentamicin-loaded SLMs (batches A1-A3, B1B3 and C1-C3). The unloaded SLMs (D1-D3) were also prepared. The formulation compositions are shown in Table 1.

The particle size and morphology of the SLMs were determined by computerized image analysis. Briefly, approximately $5.0 \mathrm{mg}$ of the SLMs from each batch was dispersed in distilled water and smeared on a slide (Marinfield, Germany) using a glass rod. It was then covered with a cover slip and viewed with a photomicroscope (Hund®, Weltzlar, Germany) attached with a digital camera at a magnification of $1000 x$. With the aid of the software in the photomicroscope, the particle morphologies were observed and photomicrographs taken. The sizes of the particles were measured and average taken.

\section{Determination of encapsulation efficiency (EE) and Loading capacity (LC)}

Approximately $0.5 \% \mathrm{w} / \mathrm{v}$ dispersion of the SLMs in distilled water was prepared, allowed to equilibrate for $48 \mathrm{~h}$ at room temperature, shaken and filtered. The filtrate was adequately analyzed for gentamicin content spectrophotometrically (Unico 2102 PC UV/Vis Spectrophotometer, USA) at $203 \mathrm{~nm}$. The amount of drug encapsulated in the SLMs was calculated with reference to a standard Beer's plot for gentamicin to obtain EE using Eq 1 [13].

$\mathrm{EE}(\%)=(\mathrm{Da} / \mathrm{Dt}) 100$

where $\mathrm{Da}$ and $\mathrm{Dt}$ are actual and theoretical drug contents, respectively.

LC expresses the ratio between the entrapped active pharmaceutical ingredient (API) and total weight of the lipids [18], and was computed as in Eq 2.

$\mathrm{LC}=\left[\mathrm{W}_{\mathrm{a}} / \mathrm{W}_{\mathrm{l}}\right] \times 100$

where $W_{1}$ is the weight of lipid added in the formulation and $W_{a}$ is the amount of API entrapped by the lipid.

\section{Time-resolved pH-dependent stability studies}

The $\mathrm{pH}$ of dispersions of the SLMs from each batch was determined using a $\mathrm{pH}$ meter (Suntex TS - 2, Taiwan) after one week, 1 and 3 months of storage.

\section{In vitro drug release studies}

Phosphate bufferred saline (PBS, $\mathrm{pH} 7.4$ ) and the USP XXII rotating paddle apparatus (Erweka, Germany) were employed for this release study. The dissolution medium consisted of $500 \mathrm{~mL}$ of freshly prepared PBS maintained at $37 \pm 1{ }^{\circ} \mathrm{C}$ by means of a thermostatically controlled water bath. The polycarbonate dialysis membrane used was pre-treated by soaking it in PBS for $24 \mathrm{~h}$ prior to the commencement of each release experiment. In each case, $300 \mathrm{mg}$ of the formulated SLMs was placed in the dialysis membrane containing $5 \mathrm{~mL}$ of the PBS, securely tied with a thermo-resistant thread and then immersed in PBS under agitation provided by the paddle at $100 \mathrm{rpm}$. At $60 \mathrm{~min}$ intervals, $10 \mathrm{ml}$ portions of PBS were withdrawn and replaced with equal volume of PBS to maintain sink condition, filtered and analysed spectrophotometrically at $341 \mathrm{~nm}$. The amount of drug released at each time interval was determined with reference to the standard Beer's plot for gentamicin in PBS. This test was replicated for all the batches, gentamicin pure sample and commercial gentamicin injection.

\section{Antimicrobial studies}

The antimicrobial activity of the SLMs was tested against clinical isolates of Staphylococcus aureus and Pseudomonas aeruginosa by agar diffusion technique [12] using samples withdrawn during the in vitro drug release studies. Molten nutrient agar was inoculated with $0.1 \mathrm{ml}$ of Staphylococcus aureus broth culture. It was mixed thoroughly, poured into sterile petri dishes and rotated for even distribution of the organism. The agar plates were allowed to set and a sterile cork borer was used to bore three cups in the seeded agar medium. Using a sterile syringe, a definite volume withdrawn from the receptor compartment of the diffusion apparatus at predetermined time intervals was used to fill the holes. The plates were allowed to stand at room temperature before incubating at $37 \pm 1{ }^{\circ} \mathrm{C}$ for 24 $\mathrm{h}$. The diameter of each inhibition zone was measured and the average determined [5]. The procedure above was repeated for Pseudomonas aeruginosa.

\section{Statistical analysis}

All experiments were performed in replicates for validity of statistical analysis. Results were expressed as mean \pm SD. ANOVA and Student's t-test were performed on the data sets generated using SPSS. Differences were considered significant at $p<0.05$. 


\section{RESULTS}

Table 2 shows the particle sizes and timeresolved $\mathrm{pH}$ values of the SLMs. The results indicate that gentamicin-loaded SLMs and unloaded SLMs had a mean particle size $(n=30)$ range of $1.49 \pm 0.05$ to $3.55 \pm 0.09$ and $1.47 \pm$ 0.02 to $1.51 \pm 0.07 \mu \mathrm{m}$, respectively. It also shows that, after three months of storage, drugloaded SLMs and unloaded SLMs showed mean $\mathrm{pH}$ range of $3.27 \pm 0.11$ to $3.29 \pm 0.08$ and 4.23 \pm 0.09 to $6.18 \pm 1.97$, respectively. The photomicrographs (pictures not shown) showed that the SLMs were discrete and had a greenish and spherical appearance. The EE of the SLMs was in the range of $57.20 \pm 0.96$ to $94.60 \pm 1.89$ $\%$. EE (Table 2) increased with increase in the concentration of gentamicin for all batches. So, batches $\mathrm{C} 1-\mathrm{C} 3$ gave the highest $\mathrm{EE}$ while batches A1-A3 gave the least. Table 2 also shows that maximum LC of $62.00,64.30$ and $70.80 \mathrm{~g}$ of gentamicin per $100 \mathrm{~g}$ of lipid were obtained for batches $\mathrm{C} 1-\mathrm{C} 3$ respectively containing $3 \% \mathrm{w} / \mathrm{w}$ gentamicin.

The release profiles of gentamicin from the SLMs in PBS are depicted in Fig. 1. A characteristic feature of the release profile of gentamicin from the SLMs is the biphasic pattern of release. Drug release from the SLMs followed the order: C1-C3
$>\mathrm{B} 1-\mathrm{B} 3>\mathrm{A} 1-\mathrm{A} 3$. The in vitro release profiles indicate very significant release of gentamicin from the SLMs. In batch A formulations, subbatch A3 gave a maximum release of $90 \%$ while sub-batch $\mathrm{A} 1$ gave the least (maximum release, $68 \%$ ). Similarly, in batch B formulations, subbatch B3 released the highest amount (i.e., 94 $\%)$ of the drug while sub-batch $B 1$ released the least amount (75\% of the drug). Furthermore, in batch $\mathrm{C}$ formulations, sub-batch C3 gave a maximum release of $99 \%$ while sub-batch C1 released $81 \%$ of the encapsulated drug. Commercial gentamicin injection (G1) and gentamicin pure sample (G2) gave $63 \%$ and 60 $\%$ drug release, respectively. The results of the bioactivity recorded as inhibition zone diameter (IZD) (Tables 3 and 4) indicate that gentamicinloaded SLMs produced very significant IZD against Gram positive organism ( $S$. aureus) and Gram negative organism ( $P$. aeruginosa). The formulations recorded increasing IZDs against the organisms with time. Moreover, gentamicinloaded SLMs gave greater IZDs than the plain gentamicin as well as commercial gentamicin injection against the organisms. Overall, subbatch C3 containing the highest PEG-4000 and drug gave the greatest IZD against Staph aureus $(27.49 \pm 2.38 \mu \mathrm{m})$ and Ps. aeruginosa (29.40 \pm $3.07 \mu \mathrm{m})$ compared with other SLMs.

Table 2: Some physical parameters of the SLMs

\begin{tabular}{|c|c|c|c|c|c|c|}
\hline \multirow[t]{2}{*}{ Batch } & \multirow{2}{*}{$\begin{array}{c}\text { Particle } \\
\text { size }(\mu \mathrm{m})^{a, b}\end{array}$} & \multicolumn{3}{|c|}{$\mathrm{pH}^{\mathrm{a}, \mathrm{c}}$} & \multirow{2}{*}{$\begin{array}{c}E E \\
(\%)^{a, c}\end{array}$} & \multirow{2}{*}{$\begin{array}{c}\text { LC } \\
\text { (g API/100 } \\
\text { lipid) }{ }^{c}\end{array}$} \\
\hline & & 1 week & 1 month & 3 months & & \\
\hline $\mathrm{A}_{1}$ & $1.49 \pm 0.05$ & $4.20 \pm 0.05$ & $4.25 \pm 0.30$ & $4.24 \pm 0.04$ & $57.20 \pm 0.96$ & 27.00 \\
\hline $\mathrm{A}_{2}$ & $1.56 \pm 0.08$ & $4.31 \pm 0.12$ & $4.30 \pm 0.08$ & $4.29 \pm 0.05$ & $61.77 \pm 0.88$ & 32.20 \\
\hline$A_{3}$ & $1.53 \pm 0.07$ & $4.21 \pm 0.17$ & $4.27 \pm 0.02$ & $4.23 \pm 0.09$ & $65.10 \pm 1.73$ & 40.60 \\
\hline $\mathrm{B}_{1}$ & $2.53 \pm 0.15$ & $5.49 \pm 0.11$ & $5.46 \pm 0.07$ & $5.47 \pm 0.25$ & $76.34 \pm 1.14$ & 44.00 \\
\hline $\mathrm{B}_{2}$ & $2.70 \pm 0.04$ & $5.50 \pm 0.02$ & $5.49 \pm 0.10$ & $5.48 \pm 0.22$ & $80.96 \pm 1.22$ & 51.70 \\
\hline $\mathrm{B}_{3}$ & $2.54 \pm 0.12$ & $5.46 \pm 0.17$ & $5.48 \pm 0.09$ & $5.45 \pm 0.03$ & $88.20 \pm 1.99$ & 59.50 \\
\hline $\mathrm{C}_{1}$ & $3.55 \pm 0.09$ & $6.10 \pm 2.45$ & $6.13 \pm 2.45$ & $6.11 \pm 2.45$ & $90.55 \pm 1.58$ & 62.00 \\
\hline $\mathrm{C}_{2}$ & $3.50 \pm 0.13$ & $6.15 \pm 0.82$ & $6.12 \pm 0.82$ & $6.13 \pm 0.82$ & $92.75 \pm 1.65$ & 64.30 \\
\hline $\mathrm{C}_{3}$ & $3.52 \pm 0.06$ & $6.17 \pm 1.97$ & $6.20 \pm 1.97$ & $6.18 \pm 1.97$ & $94.60 \pm 1.89$ & 70.80 \\
\hline $\mathrm{D}_{1}$ & $1.47 \pm 0.02$ & $3.27 \pm 0.12$ & $3.30 \pm 0.05$ & $3.28 \pm 0.07$ & - & - \\
\hline $\mathrm{D}_{2}$ & $1.51 \pm 0.07$ & $3.28 \pm 0.04$ & $3.27 \pm 0.12$ & $3.29 \pm 0.08$ & - & - \\
\hline $\mathrm{D}_{3}$ & $1.50 \pm 0.03$ & $3.31 \pm 0.03$ & $3.30 \pm 0.02$ & $3.27 \pm 0.11$ & - & - \\
\hline
\end{tabular}

${ }^{a}$ Mean $\pm S D,{ }^{b} n=30,{ }^{C} n=3$; Batches $A_{1}-A_{3}, B_{1}-B_{3}$ and $C_{1}-C_{3}$ are gentamicin-loaded SLMs while batches $D_{1}-D_{3}$ are unloaded (zero-drug) SLMs; EE = encapsulation efficiency, $L C=$ loading capacity 


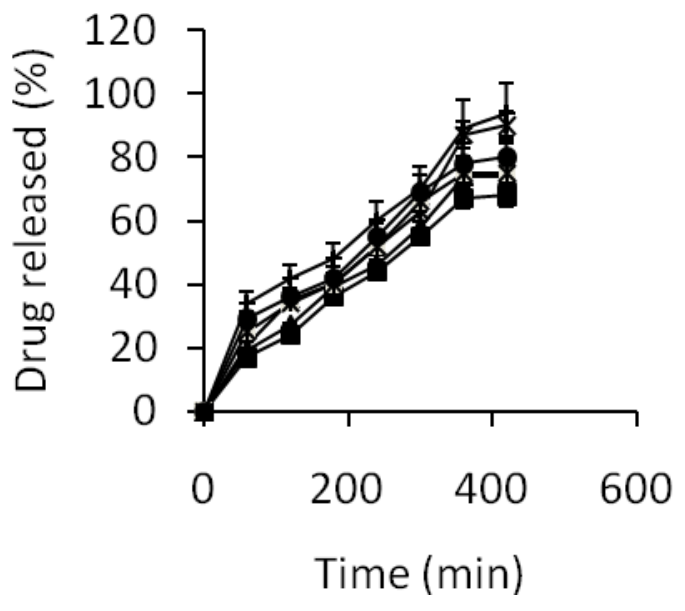

(a)

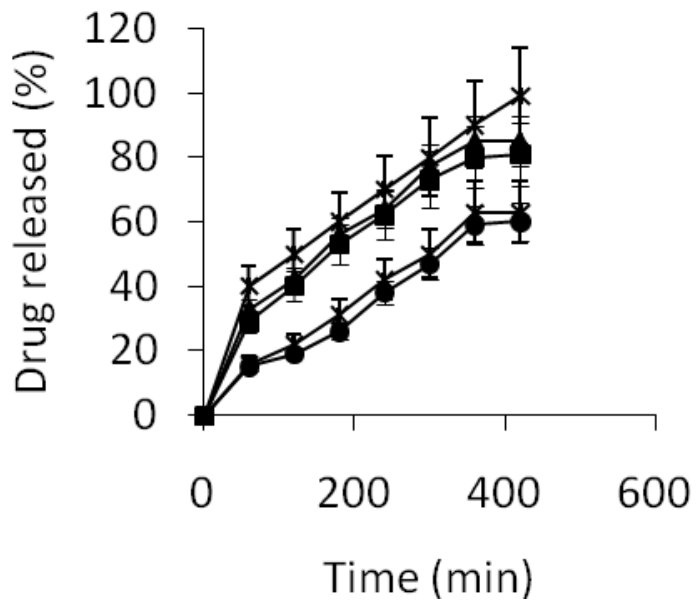

(b)

Fig. 1: In vitro release profile of gentamicin from (a) $A_{1}-A_{3}$ and $B_{1}-B_{3} S L M s(b) C_{1}-C_{3} S L M s, G_{1}$ and $G_{2}$ in PBS, pH $7.4(n=3)$. Key: $A_{1}, C_{1}(\boldsymbol{\bullet}) ; A_{2}, C_{2}(\Delta) ; A_{3}, C_{3}(\times) ; G_{1}, B_{1}(X) ; G_{2}, B_{2}(\bullet) ; B_{3}(+) . A_{1}-A_{3}, B_{1}-B_{3}$ and $C_{1}-C_{3}$ contain 1.0, 2.0 and $3.0 \% \mathrm{w} / \mathrm{w}$ of gentamicin respectively while $\mathrm{G}_{1}$ and $\mathrm{G}_{2}$ are commercial gentamicin injection and plain gentamicin, respectively

Table 3: Susceptibility of Staphylococcus aureus to gentamicin in the SLMs

\begin{tabular}{|c|c|c|c|c|c|c|c|}
\hline \multirow[t]{3}{*}{ Batch } & \multicolumn{7}{|c|}{ IZD (mm) } \\
\hline & \multicolumn{7}{|c|}{ Time (min) } \\
\hline & 60 & 120 & 180 & 240 & 300 & 360 & 420 \\
\hline$A_{1}$ & $2.04 \pm 0.19$ & $3.89 \pm 0.12$ & $5.47 \pm 0.11$ & $6.78 \pm 0.54$ & $8.15 \pm 0.96$ & $10.37 \pm 1.45$ & $11.72 \pm 1.69$ \\
\hline $\mathrm{A}_{2}$ & $2.95 \pm 0.43$ & $4.07 \pm 0.35$ & $6.55 \pm 0.32$ & $7.83 \pm 0.09$ & $9.74 \pm 0.85$ & $11.91 \pm 1.73$ & $13.53 \pm 1.04$ \\
\hline $\mathrm{A}_{3}$ & $3.68 \pm 0.81$ & $5.97 \pm 0.06$ & $7.66 \pm 0.94$ & $9.34 \pm 0.87$ & $11.52 \pm 1.06$ & $13.81 \pm 1.75$ & $16.56 \pm 1.50$ \\
\hline $\mathrm{B}_{1}$ & $2.96 \pm 0.09$ & $4.37 \pm 0.08$ & $7.23 \pm 0.19$ & $10.19 \pm 1.04$ & $13.62 \pm 1.53$ & $16.89 \pm 1.44$ & $17.32 \pm 1.09$ \\
\hline $\mathrm{B}_{2}$ & $4.02 \pm 0.50$ & $5.98 \pm 0.17$ & $8.67 \pm 0.25$ & $11.87 \pm 1.23$ & $14.63 \pm 1.09$ & $17.95 \pm 1.18$ & $18.64 \pm 1.33$ \\
\hline $\mathrm{B}_{3}$ & $4.95 \pm 0.67$ & $6.62 \pm 0.88$ & $9.03 \pm 0.72$ & $12.83 \pm 0.98$ & $17.95 \pm 1.82$ & $22.56 \pm 2.07$ & $24.35 \pm 1.98$ \\
\hline $\mathrm{C}_{1}$ & $2.99 \pm 0.45$ & $4.59 \pm 1.67$ & $7.43 \pm 2.20$ & $10.96 \pm 1.79$ & $13.82 \pm 3.10$ & $17.19 \pm 2.48$ & $20.22 \pm 3.93$ \\
\hline $\mathrm{C}_{2}$ & $4.03 \pm 0.78$ & $7.29 \pm 1.09$ & $11.80 \pm 1.33$ & $15.24 \pm 2.05$ & $18.07 \pm 2.41$ & $21.26 \pm 0.99$ & $23.87 \pm 1.56$ \\
\hline $\mathrm{C}_{3}$ & $5.00 \pm 0.82$ & $8.57 \pm 1.46$ & $12.23 \pm 1.00$ & $16.04 \pm 1.72$ & $19.68 \pm 2.15$ & $23.80 \pm 2.75$ & $27.49 \pm 2.38$ \\
\hline $\mathrm{G}_{1}$ & $2.02 \pm 0.98$ & $2.46 \pm 0.74$ & $3.71 \pm 0.19$ & $5.64 \pm 0.43$ & $7.98 \pm 0.95$ & $9.16 \pm 0.79$ & $11.87 \pm 1.47$ \\
\hline $\mathrm{G}_{2}$ & $1.98 \pm 0.62$ & $2.28 \pm 0.39$ & $3.59 \pm 0.97$ & $4.77 \pm 0.56$ & $5.14 \pm 0.79$ & $7.81 \pm 0.35$ & $9.77 \pm 0.72$ \\
\hline
\end{tabular}

${ }^{a}$ Mean $\pm S D,{ }^{b} n=3, A_{1}-A_{3}, B_{1}-B_{3}$ and $C_{1}-C_{3}$ are SLMs containing 1.0, 2.0 and $3.0 \% \mathrm{w} / \mathrm{w}$ of gentamicin respectively; $\mathrm{G}_{1}$ and $\mathrm{G}_{2}$ are commercial gentamicin injection and plain gentamicin, respectively

Table 4: Susceptibility of Pseudomonas aeruginosa to gentamicin in the SLMs

\begin{tabular}{|c|c|c|c|c|c|c|c|}
\hline \multirow[t]{3}{*}{ Batch } & \multicolumn{7}{|c|}{$I Z D(m m)^{a, b}$} \\
\hline & \multicolumn{7}{|c|}{ Time (min) } \\
\hline & 60 & 120 & 180 & 240 & 300 & 360 & 420 \\
\hline $\mathrm{A}_{1}$ & $2.18 \pm 0.07$ & $4.09 \pm 0.02$ & $6.00 \pm 0.17$ & $8.13 \pm 0.70$ & $10.25 \pm 1.96$ & $12.87 \pm 1.04$ & $13.72 \pm 0.99$ \\
\hline$A_{2}$ & $3.00 \pm 0.21$ & $5.32 \pm 0.45$ & $7.19 \pm 0.06$ & $9.08 \pm 0.14$ & $11.28 \pm 1.77$ & $13.64 \pm 2.05$ & $15.00 \pm 2.87$ \\
\hline$A_{3}$ & $4.13 \pm 0.94$ & $6.83 \pm 0.17$ & $8.08 \pm 0.74$ & $10.43 \pm 1.25$ & $12.93 \pm 0.82$ & $14.48 \pm 1.90$ & $17.30 \pm 1.56$ \\
\hline $\mathrm{B}_{1}$ & $3.63 \pm 0.87$ & $5.82 \pm 0.59$ & $8.53 \pm 0.62$ & $11.95 \pm 0.89$ & $14.27 \pm 2.08$ & $17.14 \pm 3.00$ & $18.63 \pm 1.75$ \\
\hline $\mathrm{B}_{2}$ & $4.46 \pm 0.90$ & $6.37 \pm 0.67$ & $9.19 \pm 0.83$ & $12.44 \pm 2.00$ & $15.94 \pm 3.01$ & $18.86 \pm 1.98$ & $19.46 \pm 2.46$ \\
\hline $\mathrm{B}_{3}$ & $5.03 \pm 0.76$ & $8.16 \pm 0.45$ & $10.62 \pm 0.78$ & $13.95 \pm 0.83$ & $18.32 \pm 0.56$ & $23.18 \pm 2.14$ & $25.53 \pm 1.93$ \\
\hline $\mathrm{C}_{1}$ & $3.03 \pm 0.94$ & $6.18 \pm 1.02$ & $9.75 \pm 2.31$ & $12.46 \pm 1.98$ & $16.72 \pm 3.06$ & $19.09 \pm 2.84$ & $22.87 \pm 3.00$ \\
\hline $\mathrm{C}_{2}$ & $4.59 \pm 0.23$ & $7.73 \pm 0.94$ & $10.10 \pm 1.90$ & $13.89 \pm 2.09$ & $17.64 \pm 2.52$ & $21.47 \pm 1.88$ & $24.59 \pm 2.22$ \\
\hline $\mathrm{C}_{3}$ & $5.40 \pm 0.19$ & $8.28 \pm 0.08$ & $11.98 \pm 1.04$ & $14.76 \pm 1.22$ & $19.99 \pm 1.97$ & $24.00 \pm 2.55$ & $29.40 \pm 3.07$ \\
\hline $\mathrm{G}_{1}$ & $2.98 \pm 0.07$ & $3.64 \pm 0.71$ & $4.99 \pm 0.01$ & $6.05 \pm 0.33$ & $8.19 \pm 0.15$ & $10.19 \pm 1.07$ & $12.47 \pm 1.88$ \\
\hline $\mathrm{G}_{2}$ & $2.00 \pm 0.16$ & $3.19 \pm 0.05$ & $4.07 \pm 0.09$ & $5.38 \pm 0.66$ & $6.77 \pm 0.90$ & $8.15 \pm 0.03$ & $10.98 \pm 2.07$ \\
\hline
\end{tabular}

${ }^{a}$ Mean $\pm S D,{ }^{b} n=3, A_{1}-A_{3}, B_{1}-B_{3}$ and $C_{1}-C_{3}$ are SLMs containing 1.0, 2.0 and 3.0\% $\mathrm{w} / \mathrm{w}$ of gentamicin respectively; $G_{1}$ and $G_{2}$ are commercial gentamicin injection and plain gentamicin, respectively 


\section{DISCUSSION}

The physicochemical properties of the SLMs showed that high drug loading resulted in large particle sizes, consistent with earlier reports $[12,13,19]$. The stability tests were carried out to determine the $\mathrm{pH}$ stability of the SLMs when stored at different time intervals. There was an insignificant change in the $\mathrm{pH}$ of the SLMs over a period of three months, implying that there was little or no degradation of the drug and/or the excipients used in the formulations within this period of time.

EE results showed that the lipid contents improved EE of gentamicin in the SLMs. The values of LC showed improved solubility of gentamicin in the lipid matrices. In addition, the incorporation of P90G in SLMs led to the formation of structured lipid matrices, which invariably enhanced gentamicin entrapment in the core of the SLMs. Furthermore, PEG-4000 being a hydrophilic surfactant improved the solubilization of the drug within the core lipids $[5,18]$.

The percentage drug released is highly dependent on the compositions of the SLMs. The rapid release of gentamicin from the SLMs was possibly due to a burst effect caused by the leaching out of the unentrapped drug adhering to the surface of the SLMs after the initial rapid hydration and swelling. Burst release resulting in biphasic release pattern may be utilized in dosage form design [15-17]. Perhaps, there was a lot of peripheral attachment of the drug as a result of expulsion or drug migration due to solvent drag during lyophilization. Advantageously, this would lead to a high initial blood concentration of the drug and a gradual release of the remaining drug. The high and rapid release of gentamicin from the SLMs, in addition to the burst effect, may also be related to high rate of hydration and swelling of the SLMs in the medium, which might be attributed to the lipophilicity imparted on the drug by the excipients used in preparing the SLMs $[6,8]$. The subsequent slow release phase could be a consequence of the decreasing residual amount of drug in the SLMs and the build-up of drug concentration in the dissolution medium in the course of time [19].

The microbiological test was performed to establish that gentamicin did not lose activity during formulation. Additionally, the test was performed using samples withdrawn from the in vitro studies to show an increasing IZD over time during the drug release study. Gentamicinloaded SLMs produced very significant IZDs against the organisms. Gentamicin is active against $S$. aureus [2] and $P$. aeruginosa [1]. It was observed that the greater the amount of gentamicin loaded into the SLMs, the greater the IZD produced, in agreement with earlier reports $[5,12]$. The formulations thus exhibited capacitylimited antimicrobial activity. Similarly, the antibacterial activity of the formulations was concentation and time-dependent, manifested by an increasing IZD against the organisms with time. High IZDs recorded against the organisms within 60 min of the study especially with batches C1-C3 was an indication that these formulations would have exhibited the fastest release of the entrapped drug, hence the fast antibacterial activities; whereas time-dependent increases in IZDs within 420 min implies that the SLMs had potentials for sustained drug release. Moreover, all batches of the gentamicin-loaded SLMs gave greater IZDs than plain gentamicin and commercial gentamicin injection against the organisms. Overall, batch C3 gave the greatest IZD against the organisms. This formulation would be a useful alternative for enhanced delivery of gentamicin in the treatment of infections caused by gentamicin-susceptible micro-organisms, thus encouraging further development of this formulation.

\section{CONCLUSION}

The design and preparation of SRMS-based SLMs is a relatively new field of research that seeks to exploit the attractive properties of lipid carriers to improve the delivery of therapeutic molecules. The present study shows that gentamicin-loaded SRMS-based SLMs can be successfully prepared by melt-mulsification using PEG 4000, P90G and a homolipid from Capra hircus. Further studies should seek to evaluate the pharmacokinetics of these formulations in experimental animals.

\section{ACKNOWLEDGEMENT}

The authors wish to thank Phospholipid $\mathrm{GmbH}$, Köln, Nattermann, Germany and Juhel Pharmaceuticals Ltd, Awka, Nigeria, for the generous gift of Phospholipon $₫ 90 \mathrm{G}$ and gentamicin, respectively.

\section{REFERENCES}

1. El-Gendy NA, Abdelbary GA, El-komy MH, Saafan AE. Design and evaluation of a bioadhesive patch for 
topical delivery of gentamicin sulphate. Curr Drug Deliv. 2009; 6: 50-57.

2. Stephens $D$, Kli L, Robinson D, Chen S, Chang HC, Liu $R M$, Tian $Y$, Ginsburg EJ, Gao $X$, Stultz $T$. Investigation of the in vitro release of gentamicin from a poly anhydride matrix. J Control Rel. 2000; 63: 305-317.

3. Jaspart S, Bertholet P, Piel G, Dogne JM, Delattre L, Evrad B. Solid lipid microparticles as sustained release system for pulmonary drug delivery. Eur. J. Pharm. Biopharm. 2007; 65: 47-56.

4. Umeyor CE, Kenechukwu FC, Uronnachi EM, Osonnwa UE, Nwakile CD. Solid lipid microparticles (SLMs): an effective lipid based technology for controlled drug delivery. Amer J PharmTech Res. 2012; 2(6): 1-18.

5. Momoh MA, Esimone CO. Phospholipon $90 \mathrm{H}(\mathrm{P} 90 \mathrm{H})$ based PEGylated microscopic lipospheres delivery system for gentamicin: an antibiotic evaluation. Asian Pac J Trop Biomed. 2012; 2(11): 889-894.

6. Friedrich I, Muller-Goymann CC. Characterization of solidified reverse micellar solutions (SRMS) and production development of SRMS-based nanosuspensions. Eur J Pharm Biopharm. 2003; 56: $111-119$.

7. Friedrich I, Reichi S, Muller-Goymann CC. Drug release and permeation studies of nanosuspensions based on solidified reverse micellar solutions (SRMS). Int $\mathrm{J}$ Pharm. 2005; 305: 167-175.

8. Friedrich I, Papantoniou I, Muller-Goymann CC. Physicochemical characterization of a reverse micellar solution after loading with different drugs. Pharmazie. 2000; 55: 755-758.

9. Chang HI, Perrie Y, Coombes AGA. Delivery of the antibiotic gentamicin sulphate from precipitation cast matrices of polycaprolactone. J Control Rel. 2006; 110: 414-21.

10. Robert MS, Walters KA. Dermal absorption and toxicity assessment. Marcel Dekker editor, New York, United States of America: Springer-Verlag, 1998; pp 321322.
11. Drusano GL, Ambrose PG, Bhavnani SM, Bertino JS, Nafziger AN, Louie A. Back to the future: using aminoglycosides again and how to dose them optimally. Clin Infect Dis. 2007; 45: 755-760.

12. Kenechukwu FC, Umeyor CE, Ogbonna JDN, Builders PF, Attama AA. Preliminary studies on the functional properties of gentamicin in SRMS-based solid lipid microparticles. Int J Novel Drug Deliv Tech. 2011; 1(2): 130-142.

13. Umeyor CE, Kenechukwu FC, Ogbonna JDN, Chime SA, Attama AA. Preparation of novel solid lipid microparticles loaded with gentamicin and its evaluation in vitro and in vivo. J Microencapsul. 2012; 29(3): 296-307.

14. Umeyor CE, Kenechukwu FC, Ogbonna JDN, Chime SA, Attama AA. Investigation of solidified reverse micellar systems as novel carriers for oral delivery of gentamicin. J Pharm Res. 2012; 5(9): 4914-4920.

15. Attama AA, Muller-Goymann CC. Investigation of surface-modified solid lipid nanocontainers formulated with a heterolipid-templated homolipid. Int J Pharm. 2007; 334: 179-189.

16. Attama AA, Muller-Goymann CC. A critical study of novel physically structured lipid matrices composed of a homolipid from Capra hircus and theobroma oil. Int $J$ Pharm. 2006; 322: 67-78.

17. Attama AA, Nkemnele MO. In vitro evaluation of drug release from self micro-emulsifying drug delivery systems using a biodegradable homolipid from Capra hircus. Int J Pharm. 2005; 304: 4-10.

18. Attama AA, Okafor CE, Builders PF, Okorie O. Formulation and in vitro evaluation of a PEGylated microscopic lipospheres delivery system for ceftriaxone sodium. Drug Deliv. 2009; 16: 448-457.

19. Nnamani PO, Attama AA, Ibezim EC, Adikwu MU. SRMS 142-based solid lipid microparticles: application in oral delivery of glibenclamide to diabetic rats. Eur J Pharm Biopharm. 2010; 76: 68-74. 